\title{
The Spatial Structure and Evolution Educational Anxiety-Research on Provincial Panel Based on Big Data Search
}

\author{
Wenbo Cai ${ }^{1,2}$, Pingping Sun ${ }^{1}$ \\ ${ }^{1}$ Teachers College, Shihezi University, Shihezi, China \\ ${ }^{2}$ Humanities College, Tarim University, Tarim, China \\ Email: 1584569622@qq.com
}

How to cite this paper: Cai, W. B., \& Sun, P. P. (2021). The Spatial Structure and Evolution Educational Anxiety-Research on Provincial Panel Based on Big Data Search. Open Journal of Social Sciences, 9, 118-138. https://doi.org/10.4236/jss.2021.912010

Received: November 6, 2021

Accepted: December 5, 2021

Published: December 8, 2021

Copyright $\odot 2021$ by author(s) and Scientific Research Publishing Inc. This work is licensed under the Creative Commons Attribution International License (CC BY 4.0).

http://creativecommons.org/licenses/by/4.0/

\begin{abstract}
This research uses Python technology to obtain the daily Baidu index data of 175 groups of relevant vocabulary, such as "education and training" in 31 provinces and cities from 2011 to 2020. Using Baidu search index to construct a data model of "education anxiety" total index and macro variables, it explores the temporal and spatial distribution and regional characteristics of education anxiety in various provinces in China. Research shows that at the regional level, the level of educational anxiety in East China, Central South, and North China is relatively high, and it has further increased over time, and the level of educational anxiety in Southeast, Northeast and Northwest regions is also gradually increasing. At the provincial level: by 2020, 15 provinces will enter the high level of education anxiety, and the level of education anxiety in other provinces will also increase significantly. The fixed effect model found that factors such as provincial GDP, urbanization rate, and education expenditure have statistically significant effects on "education anxiety". Based on this, policy recommendations for alleviating education anxiety are put forward.
\end{abstract}

\section{Keywords}

Education Anxiety, Shadow Education Participation, Panel Data, Baidu Index, QR Analysis

\section{Raising the Problem}

People closely associate personal success, family happiness, and social harmony with education. Education has never been as anxious as it is today. Educational anxiety is most directly reflected in the anxiety of children's learning. Shadow education participation has exacerbated the level of education anxiety. Educa- 
tional anxiety is a group social behavior, which is a process of intertwining interest demands and emotional catharsis, and emotions play an important role in it. Parents use forward-looking emotions to measure the gains and losses of personal marginal interests and make decisions (He, 2010), making shadow education participation a possibility of class mobility.

With the increasingly complex competitive environment of formal education, shadow education emerged and developed rapidly. A survey conducted by the Chinese Educational Society shows that the transaction scale of the education and training market has reached 800 billion yuan, with more than 137 million students participating. Behind the booming development, false propaganda by training institutions, creating anxiety, price fraud, and taking the opportunity to collect money have caused chaos in my country's tuition market. In order to strengthen the supervision of off-campus training, on May 21, 2021, the "Opinions on Further Reducing the Work Burden of Students in Compulsory Education and the Burden of Off-campus Training" was reviewed and approved. On June 15 of the same year, the Ministry of Education established the Department of Off-campus Education and Training Supervision.

\section{Literature Review and Theoretical Analysis}

In the field of education, the theoretical relationship between education and anxiety is relatively distant, but the phenomenon of educational anxiety exists everywhere. Educational anxiety does not just fall on the children's side. Parents themselves are trapped in a prisoner's dilemma. They are in vicious competition with unknown opponents in the tuition market. To a large extent, children's anxiety is precisely the product of parental anxiety, and it also stimulates parents. Anxiety further intensified ( $\mathrm{Wu}, 2019 \mathrm{a})$. In the past, there have been studies on the relationship between students' network dependence and anxiety, academic performance, etc. There are also studies on anxiety of different groups: students are anxious about interpersonal communication and grades, parents are anxious about their children's school choice, enrollment, and examinations, teachers are anxious about students' grades, and society is anxious about education. Studies have shown that more than $60 \%$ of adolescents are anxious about exams, some teacher groups are anxious about their own educational ability, and the middle-class group has the most significant educational anxiety (Sarita \& Rajni, 2019).

The social psychological motivation of education anxiety is the inherent social beliefs, conformity behaviors, competitive psychology, pressure perception, and children's factors in the self-structure of the masses. The causes of parental education anxiety are demand and supply, theater effect, competitive crisis, and media rendering. In recent years, graduates have become more and more difficult to find employment, facing the practical problems of unemployment after graduation and low employment with high education. The high investment in early education is in sharp contrast with the low return on graduation, which is the 
underlying cause of education anxiety in our country. In addition, education anxiety is a blind motivation for parents, and it also has many positive values.

Society is a dynamic system, cooperation and competition between individuals and groups constitute a complex and changing situation in society. Weber's purpose rational action is also called instrumental rational action. It is people's earnest calculation of their actions and the possibility of reaching their goals, and the core is the most effective way to achieve their goals. Parents investment in their children's education is also an instrumental rational action to a certain extent. They use their children to carry out special training activities to achieve the goal of improving academic performance and entering high-quality schools.

Purpose rationalism has gradually evolved into the family education concept of parenting and child training (Wang, 2019). Parents use it to measure all education-related behaviors.

Taking utilitarianism as the guide to participate in various activities to enhance their own competitiveness, group behavior has gradually become a popular trend.

The result of development has gradually been manifested in competition and selection of the best. It materializes, alienates, and abstracts people's activities, causing people to lose their subjectivity, creativity, and comprehensiveness of development, resulting in extreme psychological depression and helpless loss. In terms of social relations, the law of the jungle has also permeated education and has a negative impact on education. The prominent manifestation is the alienation and opposition between individuals and society, and vicious competition is not hesitated to achieve personal goals. The analysis of the existing literature is not difficult to see that the formation and deterioration of educational anxiety is mainly caused by many factors such as improper parent education expectations, poor educational competition order, and social transformation and development (Wu, 2019b).

Domestic education anxiety focuses on the analysis of the phenomenon of education anxiety, the discussion using speculative methods, and qualitative research. In addition, there is a lack of empirical analysis of the macro-causes of education anxiety. This research uses the search behavior of big data to carry out operational measurement of educational anxiety, includes all macro indicators to quantitatively study the influencing factors of educational anxiety. The purpose of measuring education anxiety with the Baidu search index is to use macro big data to further explain the macro reasons behind search behavior, and to compare the evolution trend of search behavior in time and space, to obtain the differences between provinces, regions and regions.

\section{Research and Design}

\subsection{Research Hypotheses and Data Sources}

This study considers the factors that affect education anxiety at the macro level and proposes the following hypotheses: 
First, the GDP per capita. GDP represents the results of all resident units' production activities calculated at market prices in a certain time. This article selects the annual per capita GDP of each province as an indicator to measure the economic development level of each province. The increase in national income levels is accompanied by higher living requirements and better education pursuits. Student shadow education participation is the behavioral performance of pursuing high-quality education, the action of educational anxiety, the calculation of parents' expectations and effects, and the weighted sum of probability and value. According to recent research on shadow education participation in decision-making, people can make quick and effective judgments and decisions based on environmental and social clues when the uncertainty is high, time is tight, and the probability of improving performance is difficult to quantify. Parents' hopes for a better life are also grafted onto their offspring's academic achievements.

Hypothesis 1: The higher the per capita GDP, the higher the level of education anxiety.

Second, the development of urbanization. The urbanization rate represents the ratio of urban population to the total population, and it reflects the level of urbanization development. The development of extensive urbanization has brought about rapid economic growth and triggered a new urban-rural duality. With the increasing level of urbanization, the desire to pursue a better life has become stronger and stronger. When dealing with urbanization risks, people are often excited about the possible decision-making results, and then choose to take risks; or fear, and then avoid risks (Wang \& Wang, 2021). In the context of urbanization, the unfair education of the children of migrant workers has become prominent. In order to prevent the intergenerational transmission of poverty and keep children from losing at the starting line, people have turned their attention to the competition for educational resources, and thus feel more educational anxiety and mental pressure.

Hypothesis 2: The higher the urbanization rate of the population, the higher the level of education anxiety.

Third, the housing price factor. During the transition period, social risk factors increase, and social members' insecurities also increase. Education, housing, and medical care have become social security that people are paying more and more attention to. When the basic demand for housing requires the great efforts of members of the society to solve, uncontrolled housing prices have caused social members to worry about housing. As an important social risk in contemporary society, housing prices play a very important role in deepening people's social anxiety. "House prices" and their changes are important factors affecting social psychology. The soaring house prices make people feel pressure and anxiety. When housing prices surge, will the anxiety of members of society affect education? Will they cast their hopes on education?

Hypothesis 3: The higher the regional housing price, the higher the level of 
education anxiety.

Fourth, the Gini coefficient. The Gini coefficient is an important indicator that reflects the degree of dispersion and distribution of measured data. It is used to measure the degree of equilibrium of development. The more the rich and the poor in the province tend to divide, the society will become more dissatisfied with education, and the people's demand for fair education will increase. By constructing the provincial Gini coefficient to measure the horizontal equity of education, it is helpful to understand the deep-seated reasons of education anxiety from the perspective of equity.

Hypothesis 4: The higher the Gini coefficient, the higher the level of education anxiety.

Fifth, education expenditure. Education expenditure is an important indicator to measure the amount of education input, reflecting the annual control of education funds in various provinces. The higher the level of government funding, the higher the degree of equalization of urban and rural education. It also shows the degree of government's emphasis on education. Relevant statistics show that the total education expenditure of economically developed provinces is higher than that of the central region ( $\mathrm{Ma} \& \mathrm{Ma}$, 2009). Education expenditures, to a certain extent, indicate the people's expectations for high-quality education. In the case of insufficient investment in education, the greater the expenditure on education, the greater the demand for education and the higher the level of education anxiety. Establishing a set of education financial investment system based on sufficient, fair and efficient education is the basic consideration for the good life that the people expect. In order to effectively meet the people's educational expectations, only balanced and sufficient education fiscal expenditures can guarantee the realization of high-quality education.

Hypothesis 5: The greater the difference in education expenditure within a province, the higher the level of education anxiety.

Sixth, the number of undergraduate graduates. The expansion of college enrollment, the popularization of higher education, the increasing number of college students, and the inability of college students to find jobs in time has aroused the attention of all sectors of society. The unemployment problem of college graduates is not only related to the stability of the society and the healthy life of the people, but also related to the precise school and professional selection behaviors of thousands of parents in reporting their volunteers. The surge in the number of undergraduate graduates has made employment pressure more and more intense, and people's demand for quality education has also increased.

Hypothesis 6: The greater the number of college graduates in the province, the higher the level of education anxiety.

Unemployment is a very concerned issue in modern economic society, and it also means that people are struggling with the dilemma of reduced income. The urban registered unemployment rate index can properly count the unemployment status. The data of this indicator is publicly available, and there are unemployment rate indicators with continuous data by year and by province. From 
the statistical scope of the data and statistical methods, the registered unemployment rate in cities and towns can reflect the unemployment status of groups with employment difficulties. When the number of unemployed people showed an increasing trend year by year, they expressed that they needed the government to provide reemployment assistance. In addition to obtaining employment assistance provided by the government, the demand for vocational training and education closely related to it is also imminent.

Hypothesis 7: The greater the number of urban unemployment registered in the province, the higher the level of education anxiety.

It should be noted that the data on per capita GDP, urbanization rate data, education expenditure, provincial annual average population, the number of undergraduates, and the number of registered unemployed persons in urban areas are all derived from data from the National Bureau of Statistics in 2011-2019. Among them, the province's urbanization level uses "urban permanent population divided by total population" as the measurement indicator. House prices are obtained by China Real Estate Index System, which is a set of index system and analysis used by the Development Research Center of the State Council, China Real Estate Association, and China Real Estate Development Group to reflect the operating conditions and development trends of the real estate market in major cities across the country in the form of price indexes method. This article selects the average annual housing price of each province as an index to measure the housing price of the province. Due to space limitations, the descriptive statistics of other explanatory variables are no longer presented here.

\subsection{Social Anxiety Index}

This paper constructs a vocabulary of 175 search hot words, uses Python technology to collect it on the Baidu Index platform. The scope of the collection is the daily search popularity of 31 provinces in China from 2011 to 2020, and then sum up and then perform logarithmic processing. The "education anxiety" search index constructed in this way can better measure regional education anxiety for the following reasons: First, according to the 47th "China Internet Development Statistics Report" released by the China Internet Information Center, as of December 2020. The number of Internet users in China has reached 989 million. According to China's 1.4 billion population, there are $70.6 \%$ of Internet users in China, the Internet penetration rate has reached more than $70 \%$. The Baidu search index is weighted and formed keyword retrieval data, which can reflect the needs of netizens to actively search for various types of information through the Baidu search engine. Through the Baidu search index, we can obtain detailed data of netizens searching for a certain keyword. These data have multiple latitudes, including specific data for each province, as well as data by city, including year, month, week, and day data. Portraits, gender, and age distribution of netizens.

People entering search keywords on search engines is an active selection 
process and a problem-driven behavior. People's search for related keywords cannot be used as a direct measure of their degree of educational anxiety, but search behavior is a subjective choice of problem-conscious individuals, indicating that they have indeed encountered problems and confusions about shadow education choices and participation, and they perceive others to participate. Shadow education has had an introverted influence on themselves and has a positive response to their behaviors, or their relatives and friends have problems with extracurricular tutoring, so they hope to find out which educational tutoring institution is better through Baidu. What are the forms of tutoring to help individuals choose better education and training institutions, etc. Second, based on daily observations, literature review, and keyword clustering, this article constructs a keyword entry related to "education anxiety". The entry includes 175 key words related to education, and the specific classification is as follows: training institution Key words such as names, teaching subjects, answering skills, education hotspots, and prestigious school enrollment. Individuals' retrieval of relevant vocabulary not only means that the individual perceives the importance of education, but also represents peer pressure as a kind of social facts. The individual has an impact. General and vocational education-related policies hinder the implementation of the school system, intensify competition for further studies and parents' education anxiety. Parents will learn about relevant policy information due to education anxiety and make the best decision.

Taking the promotion of elementary school to junior high school as an example, the reason why "promotion" connected with the mentality of education anxiety is that there are hidden concerns of parents about their children's school choice, and the actions of externalization are manifested in shadow education participation. Whether it is children or parents, many people are faced with related education problems such as "push kids to be the best", "junior connection", "high school entrance examination", "college entrance examination" and "involution", which means that education anxiety has become a social fact. Not only is education anxiety, people's search for training institutions, higher education, college entrance examination, contains people's emotional response to education anxiety, so individuals associate with keywords such as education training, senior high school entrance examination, and college entrance examination. People's retrieval behavior not only represents the psychological condition of the individual level, but also represents the influence of the negative social mentality pervading the social level on the individual, and the latter will in turn strengthen the negative social mentality.

Not only is education anxiety, people's search for training institutions, higher education, college entrance examination, contains people's emotional response to education anxiety, so individuals associate with keywords such as education training, senior high school entrance examination, and college entrance examination. People's retrieval behavior not only represents the psychological condition of the individual level, but also represents the influence of the negative social mentality pervading the social level on the individual, and the latter will in 
turn strengthen the negative social mentality.

Finally, using the Baidu search index of "educational anxiety" related vocabulary to measure education anxiety can avoid the bias problems caused by traditional subjective questionnaires. Individual cognition is affected by the surrounding environment, timing, and experience. Different individuals and the same individual may give completely different answers to the same question in different situations; in addition, in order to meet social expectations, or for self-presentation and impression management, when answering the questionnaire, the individual will hide the bad side and try to establish a good and positive image. Scholars have found that using subjective questionnaires to measure participation in psychological counseling, individuals with same level may give different answers, and the same individual may give different answers at different times. In addition to facing individual cognitive problems, it also faces the phenomenon of "stigmatization" of psychological problems. The society holds some discriminatory attitudes towards psychological problems and people with psychological problems. The social anxiety and educational anxiety of adolescents are usually not found because they are unwilling to discuss their mental health. Affected by this, some student groups will conceal the true situation in order to meet social expectations, will not take the initiative to seek outside help when encountering psychological problems such as education anxiety. This has caused some individuals to conceal their true conditions during the questionnaire survey stage. Using the Baidu search index to measure social anxiety can effectively solve this problem. The Internet naturally has the characteristics of anonymity, and Internet users are hidden behind electronic devices such as computers and mobile phones. When individual students encounter psychological dilemmas such as communication anxiety and education anxiety and are ashamed to ask others for help, the Internet provides them with a natural shelter. Through Baidu search, individuals can obtain education anxiety without exposing personal privacy. Related Information. Therefore, the Baidu search index of "educational anxiety" related words can better measure the level of educational anxiety.

\subsection{Research Methods}

This study constructed a panel data containing relevant variables of the "education anxiety" index of 31 provinces from 2011 to 2019. The model is set as follows:

$$
\begin{aligned}
\ln \left(E A_{i t}\right)= & \beta_{0}+\beta_{1} \ln \left(G D P_{i t}\right)+\beta_{2} \text { urban }_{i t}+\beta_{3} \ln \left(\text { price }_{i t}\right)+\beta_{4} \ln \left(\text { popu }_{i t}\right) \\
& +\beta_{5} \text { Gink }_{i t}+\beta_{6} \ln \left(\text { spend }_{i t}\right)+\beta_{7} \text { graduates }_{i t}+\beta_{8} \text { unemploy }_{i t} \\
& +V_{i}+\delta_{i t}, \quad i=1,2, \cdots, n ; t=1,2, \cdots, T
\end{aligned}
$$

In the above model, $E A$ represents the "education anxiety" index as the explained variable; the explanatory variables include the following: $G D P$ represents per capita regional product; urban represents the urbanization rate; price represents the average annual housing price of the city; popu represents the an- 
nual average population of each province, As a control variable; Gink represents the provincial education Gini coefficient, used to reflect the degree of wealth balance; spend represents the annual provincial education expenditure, used to reflect the scale of urban education expenditure; graduates represents the number of college graduates. Unemploy represents the number of unemployed people in urban areas. The unobservable random variable vi represents the intercept term of individual heterogeneity, that is, the "unobservable effect model". $\delta_{i t}$ represents the disturbance term that changes with the individual and time. Since each city has differences in culture and environment, these factors basically do not change over time, so this article considers the use of a two-way fixed effects model.

\section{Temporal and Spatial Characteristics and Empirical Analysis of "Education Anxiety"}

\subsection{Regional Characteristics}

In order to study the changing trend of national education anxiety, 31 provinces were further divided spatially. According to the administrative divisions of the People's Republic of my country as stipulated in the Constitution of China, in addition to Hong Kong, Macao and Taiwan, North China, Northeast China, East China, South Central, Southwest, and Northwest China are used to represent the geographic distribution of my country's 31 provinces. Among them, North China (NC) includes Beijing, Tianjin, Hebei, Shanxi, and Inner Mongolia; East China (EC) includes Anhui, Shandong, Shanghai, Jiangsu, Zhejiang, Fujian, Jiangxi, and Northeast China (NE) includes Liaoning, Jilin, and Heilongjiang. The Southwest Region (SW) includes Chongqing, Sichuan, Guizhou, Yunnan, and Tibet, the Central South Region (CS) includes Henan, Hubei, Hunan, Guangdong, Guangxi, and Hainan, and the Northwest Region (NW) includes Shaanxi, Gansu, Qinghai, Ningxia, and Xinjiang. By adding up the ten-year total index mapping for each province, the purpose is to observe the differences in changes in education anxiety between different regions (see Figure 1).

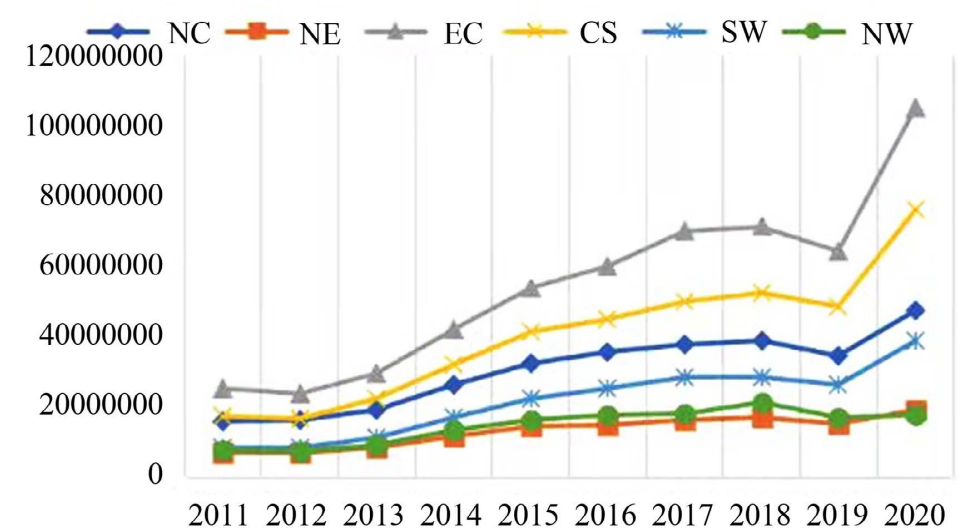

Figure 1. The level of regional education anxiety. 
The education anxiety index of NC, NE, EC, CS, SW, and NW showed a fluctuating upward trend from 2011 to 2018, while NE and NW grew slowly. In 2019, the national search index showed a fluctuating downward trend. In 2011, the EC region's education anxiety. The level is higher than that of CS, NC, NE, NW, and SW regions are almost at the same level, and the level of education anxiety in each region has increased slowly from 2011 to 2012. From 2012 to 2013, the level of EC education anxiety began to grow rapidly. Correspondingly, CS and SW increased sharply. The growth of NC and NW was relatively slow, while the growth rate of NE and NW education anxiety was flat. From 2013 to 2014, the EC, CS, NE, SW, and NW regions all showed a substantial growth trend, and the growth rate was arranged in descending order: $\mathrm{EC}>\mathrm{CS}>\mathrm{NC}>\mathrm{SW}>\mathrm{NW}>\mathrm{NE}$. From 2014 to 2015, the growth rate of NW and NE slowed down, and the EC, CS, and SW education anxiety index showed a rapid growth trend. The growth rate of EC slowed down from 2015 to 2016, as did other regions. There was differentiation in 2016-2017. The EC education anxiety index gradually climbed and there was a rapid surge. CS, SW, and NC grew steadily, while the NE and NW area education anxiety index hardly changed. In 2017-2018, EC, SW, and NC entered a weak stage, CS and NW began to grow steadily, and NE growth was very slow. There was a downward trend in various regions from 2018 to 2019. From 2019 to 2020, the EC, CS, NC, and SW education anxiety index increased sharply, while the NW education anxiety level increased slowly, and the NE education anxiety index showed a steady increase.

\subsection{Inter-Provincial Characteristics}

Taking provinces as a sample, the big data indicators obtained by Baidu Index are summed and logarithmically processed. The purpose is to normalize, and further divide the education anxiety of 31 provinces into five levels, and the level of education anxiety gradually increasing from [12, 17], the growth level is an interval. In order to save space, we selected 2012, 2014, 2018, and 2020 educational anxiety level data to draw a Time-space map. The color shades represent the level of educational anxiety, aiming to show the difference in the level of educational anxiety between regions. It can be seen from Figure 2(a) that in 2012, the national education anxiety was in the first range in Tibet. Within the range of $[12,13]$, the education anxiety in Qinghai, Ningxia, and Hainan was in the second range. The provinces within the third interval $[14,15]$ are Xinjiang, Gansu, Guizhou, Inner Mongolia, Yunnan, Guangxi, Heilongjiang, Tianjin, Anhui, Hunan, Fujian, Sichuan, Liaoning, Shanxi, Shaanxi, and Hubei. Beijing, Guangdong, Zhejiang, Shandong, Jiangsu, Shanghai, Hebei, and Henan belong to the fourth zone, which is within the range of $[15,16]$. In 2014 , the level of education anxiety in various provinces increased. Tibet and Qinghai belong to the second range. The provinces in the third range are Ningxia, Hainan, Xinjiang, Gansu, and Inner Mongolia. Compared with 2012, the level of education anxiety in each province has increased. The provinces newly entering the fourth zone are Guizhou, Jilin, Chongqing, Yunnan, Guangxi, Heilongjiang, Liaoning, 


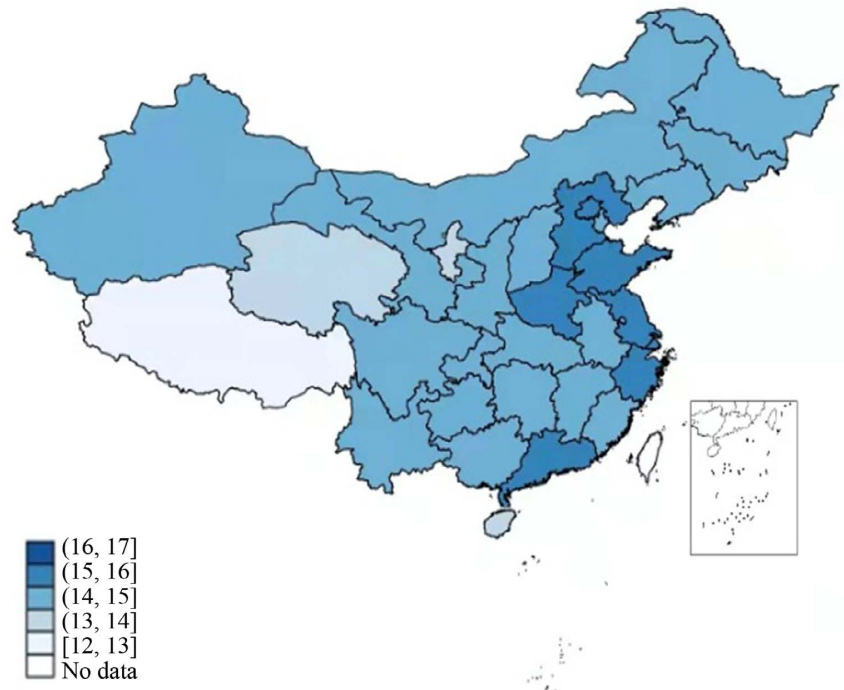

(a)

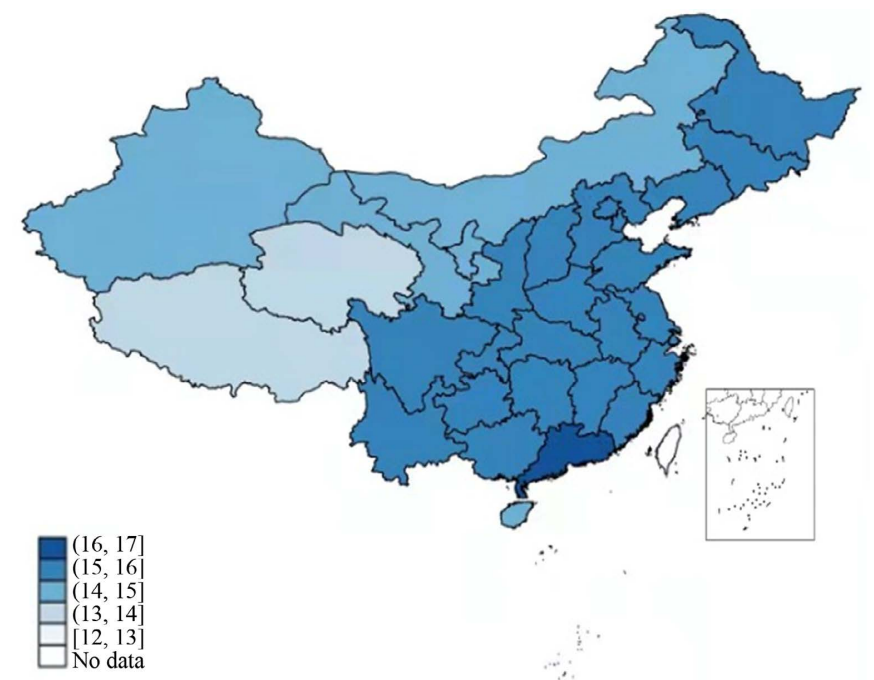

(b)

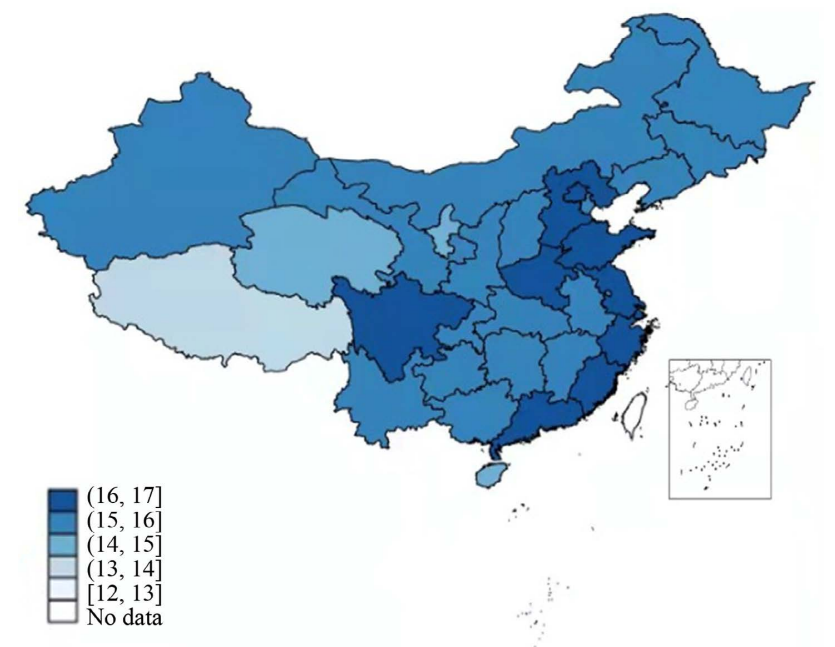

(c) 


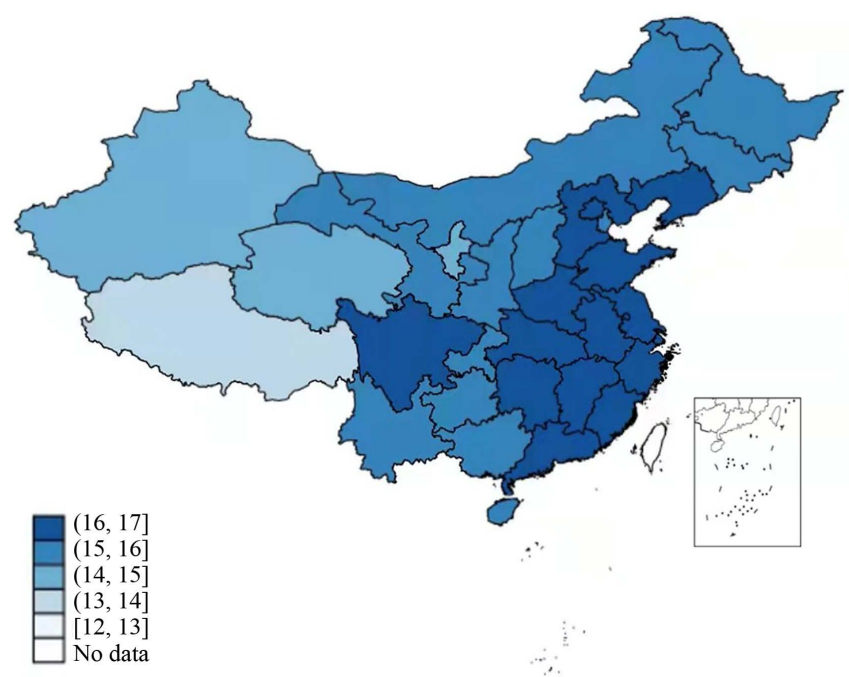

(d)

Figure 2. (a) 2012; (b) 2014; (c) 2018; (d) 2020.

Jiangxi, Anhui, Tianjin, Shanxi, Hubei, Hunan, Fujian, Shaanxi, and Sichuan. Guangdong Province is the first to enter the fifth zone and is at a high level of anxiety.

In 2018, Shanghai, Fujian and Hebei entered the fifth zone. In 2020, the level of education anxiety in Xinjiang will drop by one range, in the third range, and Hainan will enter the fourth range. The number of provinces entering the fifth zone is gradually increasing, and the new ones include Anhui, Hubei, Hunan, Liaoning, and Jiangxi. It can be seen from Figures 2(a)-(d) that the provinces with the "education anxiety" index in the fifth range are mainly concentrated in the coastal provinces and central regions, while the degree of education anxiety in the northwest region is relatively light. With the passage of time, the level of educational anxiety in coastal provinces has significantly increased, and the level of educational anxiety in the north and northwest regions has also increased significantly.

\section{Micro-Influencing Factors of "Education Anxiety"}

This paper uses panel data to verify the macroscopic influencing factors of education anxiety. In panel data, scholars generally use two-way fixed effects to make causal inferences. Two-way fixed effect, that is, the fixed effect that controls the individual fixed effect and time at the same time.

\subsection{Hausman Test}

In order to make statistics more rigorous, first use STATA16.0 for F test, and confirm that the fixed effects model is better than the mixed regression model. Second, the Hausman test is performed to determine that the fixed effects model is better than the random effects model. The test results are shown in Table 1. Show it is not difficult to see from Table 1 that the value of fix effect is much 
Table 1. Main results of Hausman test.

\begin{tabular}{cccc}
\hline variable & $\mathrm{fe}$ & $\mathrm{re}$ & $\mathrm{b}-\mathrm{B}$ \\
\hline GDP & 0.791 & 0.739 & 0.053 \\
Township rate & 1.374 & -0.051 & 1.426 \\
House price & -0.290 & -0.330 & 0.040 \\
Gini coefficient & 0.393 & 0.046 & 0.346 \\
Edu expend & 5.710 & 2.044 & 3.665 \\
Graduates & 0.266 & 0.713 & -0.447 \\
Unemployed & 0.013 & 0.003 & 0.001 \\
chi2(7) & 1162.03 & & \\
Prob $>\mathrm{F}$ & 0.0000 & & \\
\hline
\end{tabular}

larger than the value of random effect, which shows that the fixed effect model is better than the random effect model. In addition, time separate effects such as policies and emergencies need to be considered. We conducted a $t$ test under the premise of defining annual dummy variables to test the joint significance of all variables. Finally, a two-way fixed-effect model including time effects is used.

\subsection{Results of Fixed Effects Regression}

In order to test the correlation between education anxiety and macroscopic influencing factors, we conducted a two-way fixed-effects model regression test. The results are shown in Table 2. It can be seen from Table 2 that the regression coefficient of GDP is 0.379 , and the first hypothesis of this study is established. The regression coefficient of the urbanization rate is 1.745 , which is significant at the level of 0.01 . The urbanization level and social anxiety are significantly related, and the second hypothesis is established. The regression coefficient of house prices is -0.189 , which is related to zero house prices, so the third hypothesis is rejected. The regression coefficient of the Gini coefficient is -0.686 , so the fourth hypothesis is rejected. The regression coefficient of education expenditure is 0.215 , which is significant at the 0.05 level, and education expenditure and education anxiety index are statistically significantly correlated. The regression coefficient of the number of undergraduate graduates is 0.01 , which is significant at the level of 0.1 , indicating that the number of undergraduate graduates has a certain impact on the level of education anxiety. The number of unemployed people is correlated at the 0.05 level, so the seventh hypothesis is valid.

\subsection{Collinearity Test}

In order to test whether there is collinearity between macroscopic factors, this paper uses correlation coefficient method and variance inflation factor (VIF) as the test methods. Because of the multicollinearity between house price and other 
Table 2. Two-way fixed effects model regression main results.

\begin{tabular}{cccc}
\hline variable & coefficient & Standard error & $t$ value \\
\hline GDP & $0.379^{* * *}$ & 0.110 & 3.43 \\
Township rate & $1.745^{\star *}$ & 0.619 & 2.82 \\
House price & -0.189 & -0.30 & 0.068 \\
Gini coefficient & -0.686 & 0.760 & -1.11 \\
Education expend & $0.215^{*}$ & 0.09 & 1.97 \\
Graduates & 0.01 & 0.06 & 1.7 \\
Unemployed & $0.005^{* *}$ & 0.003 & 2.35 \\
Prob $>\mathrm{F}$ & 0.0000 & & \\
\hline
\end{tabular}

${ }^{* * *} p<0.001,{ }^{* *} p<0.01,{ }^{*} p<0.05,+p<0.1$.

variables, delete it. In order to find the regression of $\ln \left(E A_{i t}\right)$ on the explanatory variables, we use stepwise regression method to perform one by one, select the model with the best goodness of fit and significant coefficients. Here we will not show the steps one by one. First, obtain the strong linear relationship between education anxiety $\ln \left(E A_{i t}\right)$ and GDP in the unary linear regression equation, and the fitting degree is good. On this basis, the remaining explanatory variables are entered one by one, and the linear regression with the best fitting effect is selected based on economic significance and statistical tests. After analysis, education anxiety $\ln \left(E A_{i t}\right)$ has a significant linear relationship with GDP, Gini coefficient, education expenditure, and the number of urban unemployed people, and the fit is good. On this basis, other residual variables are introduced to finally construct a model with economic significance, statistical test, and the best fitting effect. It is obtained that education anxiety $\ln \left(E A_{i t}\right)$ has a strong linear relationship with GDP, education expenditure, and the number of unemployed people, and the fit is good, as shown in Table 3.

\subsection{Regression Analysis of Education Anxiety and Influencing Factors}

Quantile regression methods can not only present the shape of the conditional distribution, but also fully describe the variation range of the explanatory variable to the explained variable. In contrast, the least squares method uses the residual sum of squares as the objective function to minimize, which is more susceptible to extreme values, and the estimation results are not as robust as the quantile regression method. This study uses panel quantile regression $(\mathrm{QR})$ to overcome the weakness of ordinary panel regression and mean regression that are vulnerable to extreme values, and meet the needs of dynamic panel regression heterogeneity research, while effectively solving the problem of panel data endogeneity (Mao, 2016) better grasp the influence of the explained variable on the overall conditional distribution of the explanatory variable, study the influence of different influencing factors on education anxiety at different levels, and 
Table 3. Main results of collinearity test.

\begin{tabular}{ccc}
\hline Variable & VIF & $1 /$ VIF \\
\hline GDP & 5.37 & 0.346 \\
Township rate & 8.35 & 0.119 \\
Gini coefficient & 5.10 & 0.196 \\
Education spending & 4.51 & 0.220 \\
Graduates & 5.93 & 0.168 \\
Unemployed & 4.34 & 0.230 \\
Mean VIF & 5.60 & \\
\hline
\end{tabular}

conduct a comparative analysis of the explanatory variables (Yang, Liu, \& $\mathrm{Li}$, 2017). This paper uses education anxiety as the explanatory variable, and uses GDP, urbanization rate, Gini coefficient, education expenditure, the number of undergraduates, and the number of unemployed as the explanatory variables, and performs OLS and QR regressions respectively. Among them, $i$ represents the province, $t$ represents the year, $\varepsilon_{i t}$ is the random error term, and $\mu_{i}$ represents the individual effect of different provinces that does not change over time. Therefore, the panel model used in this article is:

$$
\begin{aligned}
E A_{i t}= & \beta_{0}+\beta_{1} G D P_{i t}+\beta_{2} \text { urban }_{i t}+\beta_{3} \text { popu }_{i t}+\beta_{4} \text { Gink }_{i t}+\beta_{5} \text { spend }_{i t} \\
& +\beta_{6} \text { graduate }_{i t}+\beta_{7} \text { unemploy }_{i t}+u_{i}+\varepsilon_{i t}
\end{aligned}
$$

Use the OLS and QR methods to estimate the Formula (2), as shown in Table $4 \mathrm{QR}$ estimates are set to three quantiles for regression.

Overall: the coefficients and significance of the regression of the factors affecting education anxiety are constantly changing, and the coefficient signs of all variables are basically the same under the two estimation methods (Yang \& Zhang, 2010). It proves the robustness of the regression results, most explanatory variables have high statistical significance, and the estimated coefficients are in line with theoretical expectations and the regression results are relatively reliable. For every 1 percentage point increase in GDP, education anxiety rises by $0.0343,0.208$, and 0.028 percentage points in the lower quartile, median, and upper quartile, respectively, indicating that the increase in GDP can increase the level of education anxiety to a certain extent. For every 1 percentage point increase in the urbanization rate, education anxiety rises by 1.073, 1.412, and 1.792 percentage points in the lower, middle, and upper quintiles, respectively, indicating that the increase in the urbanization rate can significantly affect the level of education anxiety. For every unit increase in the Gini coefficient, education anxiety increases significantly by $1.770,0.700$ and -0.179 percentage points in the lower, middle and upper quintiles. In the upper quartile, it will drop by 0.179 , indicating that lowering the Gini coefficient helps delay the growth of education anxiety. Our country should pay more attention to the development of education fairness and efficiency, to reduce the level of education anxiety. For 
Table 4. Regression analysis of educational anxiety and influencing factors.

\begin{tabular}{ccccc}
\hline Type & OLS & QR25 & QR50 & QR75 \\
\hline GDP & 0.208 & 0.0343 & 0.208 & 0.028 \\
Township rate & $1.412^{\star}$ & 1.073 & $1.412^{*}$ & $1.792^{* * *}$ \\
Gini coefficient & 0.700 & $1.770^{\star}$ & 0.700 & -0.179 \\
Education spend & $0.769^{* * *}$ & $0.881^{\star * *}$ & $0.769^{* * *}$ & $0.070^{* * *}$ \\
Graduates & 0.015 & 0.006 & 0.015 & $0.023^{* * *}$ \\
Unemployed & -0.003 & -0.001 & -0.002 & -0.005 \\
cons & $9.119^{* * *}$ & $9.333^{* * *}$ & $9.119^{* * *}$ & $10.560^{* * *}$ \\
$\mathrm{~N}$ & 279 & 279 & 279 & 279 \\
\hline
\end{tabular}

${ }^{\star * *} p<0.001,{ }^{* *} p<0.01,{ }^{\star} p<0.05,+p<0.1$.

every 1 percentage point increase in education expenditure, education anxiety in the lower and middle quintiles increased significantly by $0.881,0.769$, and 0.070 percentage points, respectively, indicating that the increase in education expenditure has led to an upward trend in the level of education anxiety, but the slow growth in the upper quartile indicates that education Expenditure can significantly promote education anxiety at a certain level. For every 1 percentage point increase in the number of undergraduate graduates, education anxiety in the lower quartile, median, and upper quartile will rise by $0.006,0.015$, and 0.023 percentage points, respectively, indicating that the increase in the number of undergraduate graduates will also increase the level of education anxiety. The predicted values of the linear quantile regression equation in Table 4 show the maximum possible value of the system distribution under a certain cumulative probability. The level of education anxiety can change with the change of the quantile level, and the various factors that affect education anxiety also change accordingly. This means that among multiple linear mean regression equations at different quantile levels, the regression equation with better predictive effect can be selected. This is also conducive to improving the robustness of the linear mean regression model to a certain extent, and of course it is also conducive to the accompanying Robustness of the linear quantile regression model of the mean.

In order to compare different regression results more vividly, this article uses STATA to perform quantile regression drawing, and the results are shown below.

Figure 3 depicts the confidence intervals of the regression model coefficients at different quantile levels, with quantiles varying equidistantly from 0.01 to 0.99. From the perspective of the influence of each explanatory variable on education anxiety, the dark curve in the figure represents the estimated value of the coefficient corresponding to each variable at different quantile levels, the gray area represents the $95 \%$ confidence interval of the coefficient, and the dark 

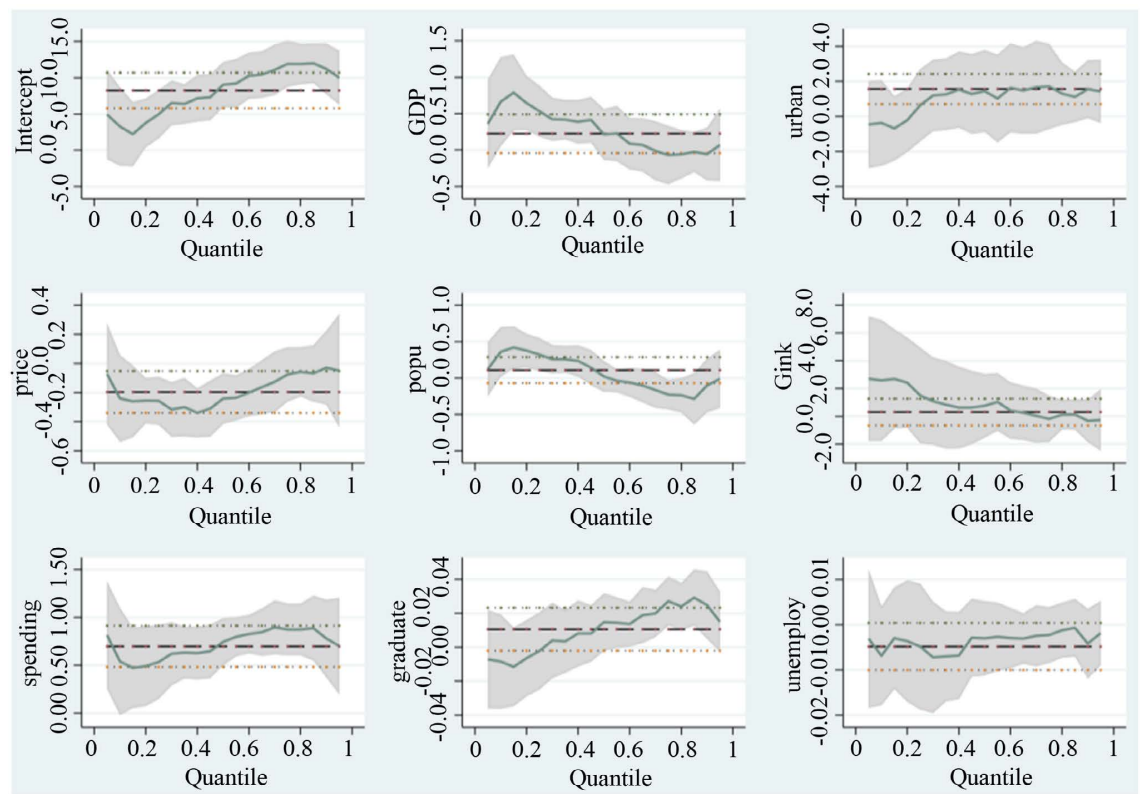

Figure 3. Main result of QR.

dotted line represents the mean regression model The estimated values of the coefficients in, between the light-colored dashed lines on both sides are the $95 \%$ confidence intervals of the coefficients in the mean regression model. As the quantile increases, the confidence interval of each coefficient will change. The coefficients of urbanization rate, education expenditure, unemployed population are estimated to be between the light-colored dotted lines, indicating that the mean regression model is reasonable. The confidence intervals of the coefficient estimates corresponding to GDP, population, and house prices first widened, then narrowed and then widened. The widening of the confidence interval of the coefficient indicates that the standard deviation of the coefficient estimate is gradually increasing, and the volatility of the coefficient estimate is increasing. In the coefficient confidence interval graph, the urbanization rate, education expenditure, and the number of unemployed people have the same impact on education anxiety at different quantile levels, and the other variables have the same effect on education anxiety at different quantile levels different. In addition, most of the estimated values of the coefficients corresponding to GDP, population, Gini coefficient, and number of undergraduates are also within the confidence interval of the coefficient of the mean regression model, which further shows that the mean regression model is reasonable to a certain extent. After Wald test GDP, urban, price, Gink, spending, graduate, unemploy are 0, F $(7,271)=170.88$, prob $>F=0.0000$, the joint equality test can show that the model is robust.

This article uses data from 2011-2019 as a sample. First, from the fixed-effect model estimation results of the balanced panel, it is found that the effects of GDP, urbanization rate, education expenditure, and the number of ordinary undergraduate graduates are positive, that is, when other factors remain un- 
changed Next, with the increase in the level of urbanization and the increase in the number of ordinary undergraduate graduates, the level of education anxiety will also increase. Further use QR quantile regression to verify that the effects of urbanization rate, education expenditure, and the number of undergraduates on education anxiety are positive and heterogeneous. For residents, the increase in GDP and urbanization rate will accelerate the level of education anxiety. The impact of the increase in education expenditure on education anxiety is complementary, and the increase in education expenditure shows that there is a large gap in education funding. The increase in the number of unemployed people has a huge impact on others. With the continuous increase in the number of unemployed people, people's demand for education has not decreased but increased, and education anxiety has also shown an increasing trend.

\section{Conclusion and Recommendations}

This research uses the Baidu search index of "education and training" related vocabulary to construct the "education anxiety" index of 31 provinces. At the same time, this data index is compared with the per capita GDP, urbanization rate, housing price, urban Gini coefficient, education expenditure, undergraduate. The number of graduates and urban unemployment data is combined to construct provincial panel data to explore the provincial differences and changing trends of China's education anxiety and analyze the factors that affect education anxiety during the transition period. The study found that: at the regional level, education anxiety has fluctuated and increased in recent years; the level of education anxiety in East China, Central South, and North China is relatively high, and has further increased over time, and the level of education anxiety in Southeast, Northeast and Northwest regions is also gradually increasing. At the provincial level: by 2020, 15 provinces will enter the high level of education anxiety, and the level of education anxiety in other provinces will also increase significantly. The fixed effect model found that GDP, population urbanization rate and education expenditure, and urban unemployed population have a significant positive impact on the provincial "education anxiety" index. QR quantile regression found that the number of undergraduate graduates promoted public education anxiety. The above research shows that more and more factors affect the promotion of educational anxiety, and people have fallen into a prisoner's dilemma in coping with educational anxiety. Based on this, policy recommendations for alleviating education anxiety are put forward.

First, jointly create a fair, just, and harmonious social environment. The government and other relevant departments should continue to promote the development of people's livelihoods, such as education, medical care, and employment, and continuously improve the social security system to effectively alleviate the survival anxiety of ordinary people, vigorously promote the high-quality and balanced development of education, starting with the balanced allocation of educational resources, further narrowing the gap in the distribution of higher 
education resources, and promoting the balanced distribution of higher education resources. Change the past competition-oriented examination selection mechanism, and continuously deepen the reform of the education system and mechanism. Speed up the reform of the high school and college entrance examination system, change the lifelong examination selection mechanism, and actively explore the comprehensive quality evaluation mechanism to reduce the proportion of test scores in the evaluation system, to provide more opportunities for students to study and develop themselves.

Second, cultivate rational, healthy, and tolerant educational concepts. Guide parents and students to establish a correct concept of success. And treat problems as learning and employment in a correct and rational manner. Parents should treat their children's education issues with an objective development perspective, and always pay attention to cultivating their children's physical and mental health, ability and expertise, and civilized qualities to promote their comprehensive development in moral, intellectual, physical, aesthetic, and labor. The primary goal of family education is to understand the laws of children's growth, respect children's individual differences and nature, protect children's imagination and creativity, and cultivate children's good habits and morals. With the rapid development of online media, online education has also become an indispensable means of education. Mainstream media should actively promote the popularization of education concepts, the essence of education, and the laws of education, to enhance the public's educational awareness and make people Be able to view school education in a correct way, set expectations rationally, avoid comparisons, follow the trend, or spend money to enter prestigious schools, and eliminate the negative impact of utilitarian values.

Third, further improve the quality, level and efficiency of public schools, and give full play to the educational functions of schools. Schools must vigorously do a good job in education and teaching research, according to the current social development status, constantly update educational concepts, optimize educational methods, enrich educational resources, enhance professional leadership, and drive parents to form correct value orientations, methods and strategies with significant educational effects, implement quality education. Strengthen the training of teachers' teaching ability, especially the ability of teachers' teaching methods, knowledge reserves, and classroom atmosphere creation. Schools should undertake activities such as helping the weak, expanding excellence, and homework, and take the initiative to assume school responsibilities.

Fourth, education and training institutions should serve as green supplements. Education and training institutions return to the nature of education for public welfare and dilute the commercial color. Returning from a profit-seeking industry to a conscientious industry, from disorderly competition to healthy development, promotes education to truly build souls and inspire wisdom. Return to the professionalism of education and the basic value of education, take patriotism, responsibility and other necessary qualities as the focus of education, 
and focus on the cultivation of key abilities. The training objectives, training content, and course design should follow the national unified standards. Strengthen industry self-discipline, take the initiative to assume social responsibilities, carry out green training, make a useful supplement to school education, and carry out various quality trainings to form positive energy for social education and create a good environment for children's growth and success.

Fifth, innovate the process supervision system to make supervision normalized and sustainable. Adhere to the problem orientation, build a scientific and standardized long-term management system for off-campus training institutions covering the whole country, clarify the responsibilities of education, public security, market supervision and other departments, promptly investigate and clean up training institutions that violate regulations and laws, and give full play to the unique role of media and public opinion supervision. Through objective, truthful, scientific and accurate reports, we will fully implement the National Opinions on Regulating the Development of Off-campus Training Institutions, create a good education ecology for joint development inside and outside schools and collaborative education.

\section{Conflicts of Interest}

The authors declare no conflicts of interest regarding the publication of this paper.

\section{References}

He, Z. (2010). The Evolution and Governance Strategies of Mass Incidents-Based on the Analysis of Collective Behavior and Western Social Movement Theory. Theory and Reform, No. 4, 105-109.

Ma, G. X., \& Ma, Z. Y. (2009). The Share of Education Expenditure in GDP: International Comparison and Policy Recommendations. Educational Development Research, 29, 8-12.

Mao, Y. (2016). Comparison of Statistical Analysis Results of Proficiency Testing Data for Data Dispersion between Quartile Method and Iteration Method. Metallurgical Analysis, 36, 76-81.

Sarita, D., \& Rajni, D. (2019). Construction and Standardization of Educational Anxiety Scale (EAS). ZENITH International Journal of Multidisciplinary Research, 9, 140.

Wang, H. C. (2019). Education Failure, Education Anxiety and Education Governance. Exploration and Contention, No. 2, 65-70.

Wang, X. T., \& Wang, N. H. (2021). The Hypothesis of Forward-Looking Emotions as the Information Source of Social Risks: Discussion on the Emotional and Cultural Mechanisms of Risk Decision-Making in Public Settings. Advances in Psychological Science, 29, 959-966. https://doi.org/10.3724/SP.J.1042.2021.00959

Wu, G. J. (2019a). Post-Human Condition and Chinese Education Practice: The End of Education or Lifelong Education-Education Philosophy in the Era of Artificial Intelligence. Journal of East China Normal University (Education Science Edition), 37, 1-15+164.

Wu, X. Y. (2019b). The Cause of Education Anxiety and the Way to Alleviate It. People's 
Forum, 24, 138-139.

Yang, W. P., \& Zhang, Z. Y. (2010). A Comparative Study on the Ecological Total Factor Productivity of the Yellow River Basin and the Yangtze River Economic Zone. Journal of Management, 33, 26-37.

Yang, X. Y., Liu, Y. Q., \& Li, J. L. (2017). Confidence Interval Calculation Method for Reliability of Photovoltaic Power Station with Energy Storage Based on Quartile Method. Transactions of the Chinese Society of Electrical Engineering, 32, 136-144. 